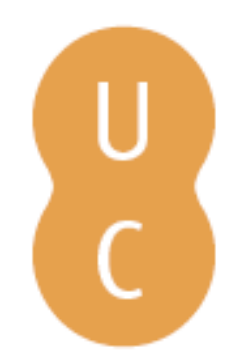

\title{
nommalina
}

\section{Por entre brasas e fumaças: a importância da abordagem sociológica da memória social de idosos para a compreensão de desastres relacionados aos incêndios florestais em Portugal}
Autor(es):
Valencio, Norma; Scopinho, Rosemeire Aparecida; Lourenço, Luciano
Publicado por:
Imprensa da Universidade de Coimbra; RISCOS - Associação
Portuguesa de Riscos, Prevenção e Segurança

URL

persistente:

DOI:

URI:http://hdl.handle.net/10316.2/34911

Accessed : $\quad$ 26-Apr-2023 14:03:45

DOI:http://dx.doi.org/10.14195/978-989-96253-3-4_111

A navegação consulta e descarregamento dos títulos inseridos nas Bibliotecas Digitais UC Digitalis, UC Pombalina e UC Impactum, pressupõem a aceitação plena e sem reservas dos Termos e Condições de Uso destas Bibliotecas Digitais, disponíveis em https://digitalis.uc.pt/pt-pt/termos.

Conforme exposto nos referidos Termos e Condições de Uso, o descarregamento de títulos de acesso restrito requer uma licença válida de autorização devendo o utilizador aceder ao(s) documento(s) a partir de um endereço de IP da instituição detentora da supramencionada licença.

Ao utilizador é apenas permitido o descarregamento para uso pessoal, pelo que o emprego do(s) título(s) descarregado(s) para outro fim, designadamente comercial, carece de autorização do respetivo autor ou editor da obra.

Na medida em que todas as obras da UC Digitalis se encontram protegidas pelo Código do Direito de Autor e Direitos Conexos e demais legislação aplicável, toda a cópia, parcial ou total, deste documento, nos casos em que é legalmente admitida, deverá conter ou fazer-se acompanhar por este aviso.

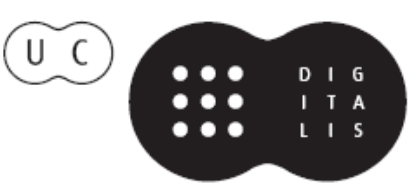



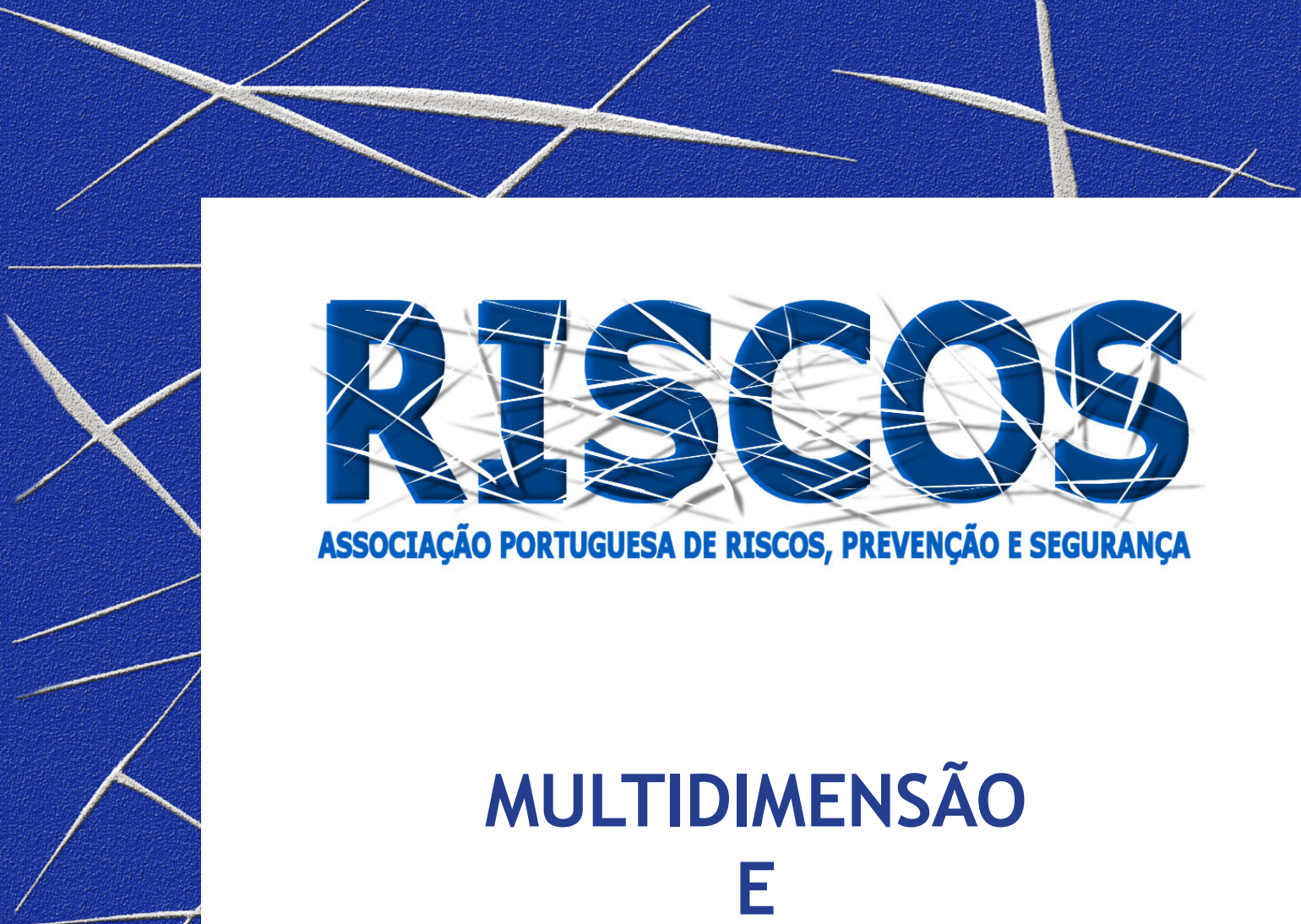

ASSOCIAÇÃO PORTUGUESA DE RISCOS, PREVENCCÃO E SEGURANÇA

MULTIDIMENSÃO

E
TERRITÓRIOS DE RISCO

III Congresso Internacional

I Simpósio Ibero-Americano

VIII Encontro Nacional de Riscos

Guimarães

2014 


\title{
POR ENTRE BRASAS E FUMAÇAS: A IMPORTÂNCIA DA ABORDAGEM SOCIOLÓGICA DA MEMÓRIA SOCIAL DE IDOSOS PARA A COMPREENSÃO DE DESASTRES RELACIONADOS AOS INCÊNDIOS FLORESTAIS EM PORTUGAL
}

\author{
Norma Valencio \\ Programa de Pós Graduação em Sociologia,Universidade Federal de São Carlos \\ Programa de Pós-Graduação em Ciências da Engenharia Ambiental, Universidade de São Paulo \\ normaf@terra.com.br \\ Rosemeire Aparecida Scopinho \\ Departamento de Psicologia e NUESTRA, \\ Universidade Federal de São Carlos \\ scopinho@ufscar.br \\ Luciano Lourenço \\ Departamento de Geografia e CEGOT, Faculdade de Letras, \\ Universidade de Coimbra \\ luciano@uc.pt
}

\begin{abstract}
RESUMO
O desvendamento da trama social implicada nas catástrofes é relevante para o aperfeiçoamento das políticas públicas no tema. Nessa trama social, incluem-se as especificidades do ponto de vista dos diferentes subgrupos sociais acerca de como vivenciaram a situação. A sociologia é uma disciplina fundamental para propiciar esse desvendamento. De um lado, os métodos próprios desta disciplina favorecem a identificação e a análise das características dos sujeitos em interação e a sua situação. De outro, esta disciplina propõe e ajusta, para cada contexto social específico, um esquema classificatório que organiza os elementos materiais e simbólicos que foram perturbados na catástrofe. Tendo isso em conta, este estudo apresenta aspectos das contribuições sociológicas, por meio do método da memória social, para o entendimento do drama de moradores idosos na vivência de incêndios florestais em oito aldeias do distrito de Coimbra, em Portugal.

Palavras-chave: Sociologia dos Desastres; Defesa Civil; Brasil.
\end{abstract}

\section{Introdução}

O debate sociológico sobre o tema dos desastres/catástrofes tem sido enfático quanto à importância que a escuta ativa dos grupos sociais afetados tem para o aperfeiçoamento das políticas públicas no tema. A tragicidade desse tipo de acontecimento se deve ao envolvimento de um dado meio social e que o vivencia em seu próprio tempo social (Quarantelli, 2005). Isso torna evidente que os esforços públicos para ampliar as possibilidades de compreensão sobre como esse meio social se organiza, funciona e elabora os seus sentidos sobre a vida e o mundo adicionam possibilidades de êxito às políticas postas em curso. Das (1995), apropriadamente, salienta que um evento crítico deixa vestígios incomodativos não apenas na organização comunitária e no embate político, mas também no corpo e na intersubjetividade. Isso provoca alterações na experiência social da vida quotidiana, incluso o aumento de tensões na relação direta com o meio técnico-operacional que atua nessas circunstâncias.

A situação dos diferentes subgrupos sociais envolvidos numa mesma catástrofe - não apenas em relação ao grau de exposição ao fator de perigo, mas também em relação à histórica vulnerabilidade correspondente à dimensão de classe, de gênero, etária, étnica, entre outros - suscita que cada um dos recortes acima construa, potencialmente, uma interpretação singular acerca dos acontecimentos. A partir de um nexo comum, cada sujeito individual ou coletivo 
pode enfatizar um dado aspecto da situação, retribuindo o peso dos elementos decisivos que contribuíram para o seu drama em particular.

A busca por um aperfeiçoamento das políticas de proteção e defesa civil, visando torná-la mais eficaz, participativa e envolvida com o saber-fazer comunitário, pode se valer dos contributos das Ciências Sociais, especialmente, da Sociologia. Isso porque o objetivo desta disciplina é, em última instância, desvendar as lógicas subjacentes à estrutura e dinâmica social. De um lado, os métodos próprios desta disciplina favorecem a identificação e a análise das características dos sujeitos em interação num determinado contexto macro ou microssocial. De outro, no que tange às catástrofes, esta disciplina pode contribuir, entre outros, na proposição de esquemas classificatórios que favorecem a compreensão dos nexos entre os elementos materiais e simbólicos e as práticas dos sujeitos envolvidos. A fim de ilustrá-lo, este estudo parte de uma apresentação sucinta do método da memória social para focalizar a contribuição do mesmo no entendimento do drama vivido por moradores idosos em contexto de incêndios florestais em oito aldeias do distrito de Coimbra, em Portugal.

\section{A importância da memória social de idosos}

Quando se busca a memória social sobre acontecimentos do passado, é pertinente buscá-la junto a um sujeito social em particular, os idosos, porque são eles os guardiões do passado (Bosi, 1979). Os idosos aninham as suas experiências longínquas de vida e as tradições de sua comunidade de convivência de modo a insinuá-las como algo pulsante, vivo, alojado nos meandros do presente. Pela memória dos idosos é possível perceber as transformações ocorridas no espaço, na história, nas instituições, nos papéis sociais e no imaginário social ao longo das gerações, ao mesmo tempo em que se percebe a manutenção de certas crenças e costumes. Para Pollak (1992), a memória social é balizada por três elementos: os acontecimentos (que caracterizam a memória que herdamos do grupo ao qual pertencemos ou mesmo a memória dos acontecimentos que vivemos pessoalmente), os personagens e os lugares. Pois são exatamente esses três os elementos indispensáveis para construir uma narrativa bem estruturada sobre uma catástrofe.

Martins (2008: 129) salienta que a memória “(..) se inscreve e se constrói no cotidiano. Ao mesmo tempo em que apreendemos a memória através do imaginário, do senso-comum, construímos memórias através de nossas relações cotidianas que se perpetuam nos gestos, sentimentos e atitudes". E a memória coletiva influencia e contempla as memórias individuais, pois “(...) não há lembranças que não reaparecem sem que de alguma forma seja possível relacioná-las ao grupo" (Halbwachs, 2006:40); isto é, para o autor, evocamos e articulamos outras memórias para referirmo-nos às nossas lembranças, aquelas que, aparentemente, são individuais.

\section{A memória acerca de catástrofes vividas}

A vivência de uma catástrofe por parte de uma comunidade é algo que permanece nítido na memória social local, posto seja um tipo de acontecimento desestruturador das rotinas da vida quotidiana. É na vida quotidiana que o espaço comunitário se apresenta como espaço vivido (Lefebvre, 1974) e os sujeitos exercitam uma autonomia relativa sobre a organização e o ritmo de sua sociabilidade corriqueira. A catástrofe, quando ocorre, desorganiza o espaço vivido e, além disso, dita uma nova dinâmica social emergencial, que busca mitigar o solapamento (em diversas gradações) das condições materiais de existência. 
O sofrimento social multidimensional havido, decorrente dos danos e prejuízos materiais e imateriais, ativa sentidos compartilhados sobre essa experiência. A memória social de idosos sobre os acontecimentos afeitos à sua comunidade é um dos melhores recursos para resgatar a dimensão relacional do problema, dado que possa fluir de modo a imbricar aspectos sociopolíticos, socioculturais, socioambientais e psicossociais.

\section{A memória de idosos aldeões em contexto de incêndio florestal}

Embasando-nos em vários estudos geográficos realizados pelo Núcleo de Investigação Científica de Incêndios Florestais (NICIF), especialmente, na cartografia dos incêndios florestais ocorridos nas últimas cinco décadas no alto distrito de Coimbra (Lourenço 2006), foi possível identificar oito aldeias que foram particurlamente sensíveis à ocorrência de incêndios florestais, a saber: no concelho de Arganil, as aldeias de Cepos e Piódão; no concelho de Góis, as aldeias de Malhada e Soito e, no concelho de Oliveira do Hospital, as aldeias de Gramaça, Chão Sobral, Aldeia das Dez e Rio de Mel.

Nas referidas aldeias, foram realizadas entrevistas individuais e coletivas com os moradores idosos, intentando buscar a sua vocalização direta sobre os piores incêndios florestais ao derredor e de que tinham lembrança e em cujo contexto trágico os mesmos tinham participado. De tipo semiestruturadas, as entrevistas seguiram um roteiro temático que procurou resgatar as recordações acerca da vivência direta dos eventos assim como dos momentos que o precederam e sucederam, tratando especialmente das suas consequências no quotidiano do modo de vida aldeão. As entrevistas coletivas que possibilitaram a calibração das informações obtidas através dos diferentes discursos individuais acerca das regularidades e especificidades da vivência dos desastres/catástrofes relacionados aos incêndios florestais.

Paralelamente ao processo de agendamento e realização das entrevistas, observámos o quotidiano aldeão, o que permitiu apreender elementos importantes do modo de vida local, desde as formas de trabalho existentes, até aos costumes e tradições mantidas, passando pela organização dos diferentes espaços de vivência. Este recurso permitiu ficar a conhecer melhor as rotinas dos sujeitos e, ao mesmo tempo, confrontar discursos e práticas sociais.

Dentre os principais resultados obtidos na interlocução com os moradores idosos entrevistados, e que são reportados com maior detalhamento em Valencio, Scopinho e Lourenço (no prelo), destacam-se:

a) uma produção discursiva que, por um lado, têm como referência as palavras vigília, alarme, combate, defesa e ajuda, componentes de uma prática ativa em prol da autoproteção e, de outro lado, apresenta palavras que revelam sentimentos de fragilidade, tais como aflição, medo e pânico;

b) uma relação ambígua, ao mesmo tempo colaborativa e de conflito, com os técnicos e operacionais de combate aos incêndios. Por um lado, os moradores empenham-se no auxílio possível aos trabalhos de resposta aos incêndios - como através da comunicação aos setores competentes acerca dos primeiros focos de incêndio, alertando diretamente os vizinhos, fornecendo equipamentos de combate, cooperando no manuseio dos mesmos e em tarefas de alimentação e dessedentação das equipes exaustas, entre outros. Contudo, as comunidades sentem que sua colaboração é socialmente invisível;

c) as tensões entre os critérios de salvamento e de evacuação impostos pelo meio técnicooperacional e os critérios comunitários, como ocorreu em Piódão, onde, num incêndio em 
2005, houve desacordo entre combatentes e moradores na definição dos indivíduos que tinham condições para ajudar;

d) as ações táticas de autoproteção comunitária frente ao perigo iminente, como ocorreu em Cepos e Malhada, onde os moradores se esconderam dentro de poças de água até que as labaredas passassem; e, por fim,

e) a identificação de sujeitos que adotam práticas de risco, que vão desde os proprietários, agrícolas e florestais, que não limpam seus terrenos até os órgãos autárquicos (Câmaras Municipais e Juntas de Freguesia) que não fazem a devida manutenção das estradas e vias públicas, passando, ainda, pelos insanos que, por divertimento ou sadismo, ateiam fogos pelo prazer de apreciar a movimentação das pessoas, dos bombeiros e outros agentes de proteção civil nas operações de combate.

\section{Conclusões}

Com a ilustração acima, consideramos que a abordagem sociológica, debruçada sobre o método da memória social de idosos, trouxe elementos preciosos para o debate sobre como superar as insuficiências das operações de combate aos incêndios florestais nas aldeias investigadas.

A nosso ver, a cultura institucional de planificação avança quando se instaura uma racionalidade dialógica com as comunidades que vivenciaram catástrofes. No geral, essas já se sentem ativamente envolvidas nas circunstâncias de catástrofe e muito apreciariam deixar de ser vistas apenas como vítimas no imaginário institucional. Quanto maior for a disposição institucional para elaborar medidas de prevenção, preparação, resposta e recuperação na tessitura integrada do saber-fazer técnico e comunitário, maiores serão as chances de evitação dos sentimentos comunitários de fragilidade e de insegurança quanto ao futuro, bem como as hipóteses de superação da sua invisibilidade social, quando no apoio às ações do meio-técnico operacional.

O repertório analítico das comunidades sobre os incêndios florestais que as afetaram no passado é, continuamente, remodelado na memória social local. A experiência de dilaceração circunstancial do espaço vivido é ressignificada tanto pelo extenso percurso de vida dos memorialistas quanto pela atualização constante do conjunto de regras e valores locais. Portanto, quanto mais perene for a relação institucional baseada numa escuta ativa às comunidades aldeãs, especialmente aos seus guardiões da memória, maior a possibilidade de apreensão técnica dos erros e acertos em cada episódio de combate ao incêndio e menos vulneráveis todos os envolvidos se sentirão.

\section{Referências Bibliográficas}

Bosı, Ecléa (1979) - Memória e sociedade: lembrança de velhos. T.A. Queiroz Editor ltda, São Paulo.

DAS, Veena (1995) - Critical Events: an anthropological perspective on contemporary. Oxford University Press, New Delhi.

HalbWaChs, Maurice (2006) - A Memória Coletiva. São Paulo: Centauro.

LefeBVRE, Henri (1974) - La production de l'espace. Paris: Anthropos.

Lourenço, Luciano (coord.) (2006) - Paisagens de Socalcos e Riscos Naturais em Vales do Rio Alva. Coletâneas Cindínicas VI. Núcleo de Investigação Científicas de Incêndios Florestais, Coimbra. Disponível: www.uc.pt/fluc/nicif/Publicacoes/Colectaneas_Cindinicas/Coletanea_Cindinica_VII [10 de julho de 2013]

MARTINS, José de Souza (1998) - “O senso comum e a vida quotidiana”. Tempo Social, Revista Soc. USP, 10(1), maio, São Paulo, p.1-8. 
Pollak, Michael (1992) - “Memória e identidade social”. Estudos Históricos, Rio de Janeiro, vol.5, n.10. p. 200-212.

QuARANTELLI, Enrico L. (2005) - “A social science research agenda for de disasters of the $21^{\text {st }}$ century: theoretical, methodological and empirical issues and their professional implementations". In PerRY, Ronald W.; QuARANTELLI, EnRICO L. (Eds.) - What is a disaster? New answers to old questions. International Research Committee on Disasters, USA, p. 325-396.

Valencio, Norma; Scopinho, Rosemeire Ap.; Lourenço, Luciano (no prelo) - “Por entre brasas e fumaças: encontros e desencontros entre práticas sociais e racionalidades operantes de sujeitos envolvidos em contextos de incêndios florestais". Cadernos de Geografia, Coimbra. 